\title{
Experimental validation of control strategies for a microgrid test facility including a storage system and renewable generation sets
}

Baccino, Francesco; Marinelli, Mattia; Silvestro, Federico; Forero Camacho, Oscar Mauricio; Isleifsson, Fridrik Rafn; Nørgård, Per Bromand

Published in:

Workshop on Integration of Renewables into the Distribution Grid 2012

Publication date:

2012

Link back to DTU Orbit

Citation (APA):

Baccino, F., Marinelli, M., Silvestro, F., Forero Camacho, O. M., Isleifsson, F. R., \& Nørgård, P. B. (2012).

Experimental validation of control strategies for a microgrid test facility including a storage system and renewable generation sets. In Workshop on Integration of Renewables into the Distribution Grid 2012 Institution of Engineering and Technology.

\section{General rights}

Copyright and moral rights for the publications made accessible in the public portal are retained by the authors and/or other copyright owners and it is a condition of accessing publications that users recognise and abide by the legal requirements associated with these rights.

- Users may download and print one copy of any publication from the public portal for the purpose of private study or research.

- You may not further distribute the material or use it for any profit-making activity or commercial gain

- You may freely distribute the URL identifying the publication in the public portal 


\title{
EXPERIMENTAL VALIDATION OF CONTROL STRATEGIES FOR A MICROGRID TEST FACILITY INCLUDING A STORAGE SYSTEM AND RENEWABLE GENERATION SETS
}

\author{
Francesco BACCINO, Mattia MARINELLI, Federico SILVESTRO \\ Division of Electrical Engineering, University of Genova - Italy \\ francesco.baccino@unige.it, mattia.marinelli@unige.it, federico.silvestro@unige.it \\ Oscar Mauricio FORERO CAMACHO, Fridrik Rafn ISLEIFSSON, Per Bromand NØRGÅRD \\ Risø DTU, Technical University of Denmark - Denmark \\ osmfc@elektro.dtu.dk, fris@elektro.dtu.dk, pern@elektro.dtu.dk
}

\begin{abstract}
The paper is aimed at describing and validating some control strategies in the SYSLAB experimental test facility characterized by the presence of a low voltage network with a $15 \mathrm{~kW}-190 \mathrm{kWh}$ Vanadium Redox Flow battery system and a $11 \mathrm{~kW}$ wind turbine. The generation set is connected to the local network and is fully controllable by the SCADA system. The control strategies, implemented on a local pc interfaced to the SCADA, are realized in Matlab-Simulink. The main purpose is to control the charge/discharge action of the storage system in order to present at the point of common coupling the desired power or energy profiles.
\end{abstract}

\section{INTRODUCTION}

The development of the electric system, due to the strong increase of the distributed and renewable generation, is posing new challenges to the management and control of the power system. Concerning the wind generation, one of the major issues is related to its production profile, hardly predictable and manageable, that could cause overloading or overvoltage [1].

A work previously presented was aimed at describing the models of generation sources and storage systems for implementing integrated control strategies of a renewable generation park composed by wind turbines and batteries. The purpose of the energy storage system was to be coupled to the wind generation system in order to realize different tasks: to have the generation output power smoothed and to grant no power transfer, for a certain period on Distribution System Operator (DSO) request, at the point of common coupling in any battery state-ofcharge condition [2].

This paper aims at improving the previously described control strategies and to test them in the SYSLAB experimental facility located in the Risø Danish Technical University (DTU) laboratories.

\section{SYSLAB NETWORK DESCRIPTION}

SYSLAB is a small-scale power system $(<100 \mathrm{~kW})$ consisting of real power components interconnected by a 3 phase $400 \mathrm{~V}$ AC power grid, and some communication and control nodes interconnected by a dedicated network, all distributed (more than $1 \mathrm{~km}$ ) over the Risø DTU
Campus. The power components include diesel gen-set, wind power, solar power, electricity storage, electrical vehicles and controllable loads. The SYSLAB power system can operate in island mode or be connected to the national power system. Focus of SYSLAB is assessment of the various systems aspects, including system architecture, control, communication and the components' system characteristics. The layout is shown in Figure 1.

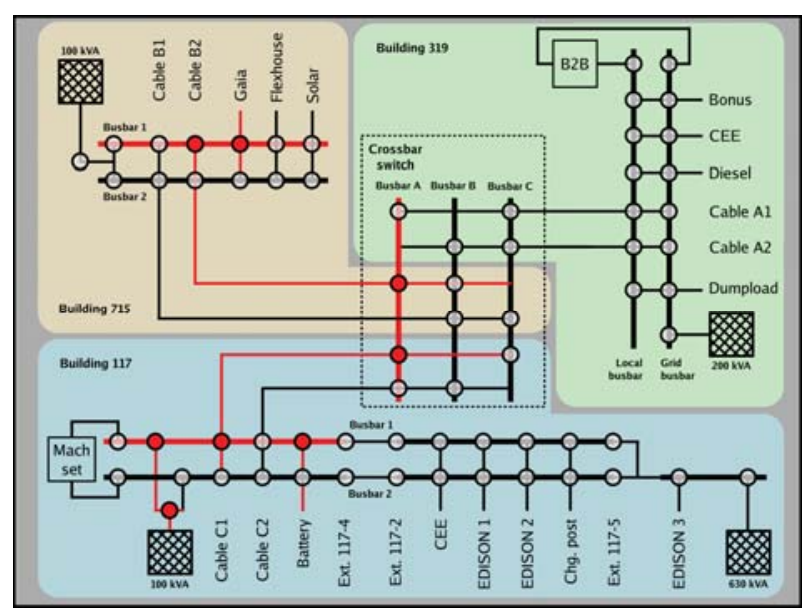

Figure 1. SYSLAB Test facility at the Risø laboratories in the experimental configuration adopted.

The experiment layout involved the use of the following components, listed in Table 1.

Table 1. SYSLAB used components

\begin{tabular}{|l|l|}
\hline Battery technology & Vanadium Redox Flow \\
\hline Manufacturer & Prudent Energy \\
\hline Nominal AC Power & $15 \mathrm{~kW}$ \\
\hline AC/DC interface & PWM; four quadrants converter \\
\hline Usable Energy & $190 \mathrm{kWh}$ \\
\hline $\begin{array}{l}\text { Response time from zero to full } \\
\text { power }\end{array}$ & 1 second \\
\hline \hline Wind Turbine technology & $\begin{array}{l}\text { Fixed pitch stall control; 2 bladed, } \\
\text { diameter } 13 \mathrm{~m} \text {; downwind passive } \\
\text { yaw }\end{array}$ \\
\hline Manufacturer & Gaia Wind UK \\
\hline AC generator & Squirrel cage induction machine \\
\hline Nominal AC Power & $11 \mathrm{~kW}$ \\
\hline Cut-in; Nominal wind & $4 ; 12 \mathrm{~m} / \mathrm{s}$ \\
\hline \hline SCADA system & $\begin{array}{l}\text { Ethernet based communication } \\
\text { network with 20 communication } \\
\text { nodes and distributed intelligent } \\
\text { control }\end{array}$ \\
\hline
\end{tabular}




\section{CONTROL STRATEGIES}

As foretold, the idea proposed in this paper is to control the battery charging and discharging in order to control the wind turbine output at the Point of Common Coupling (PCC) [3]. An overview of the system conceptual layout is shown in Figure 2. The reference battery power (named PrefBattery) is generated by the external controller, implemented in Simulink, and generates the set-point in function of the real measured output of the coupled system and of the desired power/energy profiles.

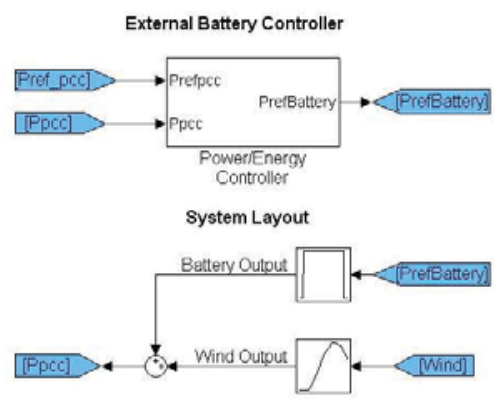

Figure 2. System conceptual configuration.

Two control strategies, named respectively Power Control and Energy Control, are analyzed and their effectiveness is tested [4], [5].

The first control strategy, named Power Control, has the task to set the reference power to the storage in order to compensate the wind farm fluctuations and to have at the PCC the desired power profile. The control is realized with the implementation of a PI (Proportional-Integral) controller with back calculation anti-windup. The proportional gain is equal to 0.4 while the time constant values 5 seconds. The main feature of this kind of control is the stiffness: in fact, if a smooth power output (time frame of 1 second) is requested, the controller will command a series of deep and very fast cycles of charge and discharge in order to compensate the fluctuation induced in the wind farm output by the turbulence.

The second control strategy, named Energy Control, differs from the previous one because it is more elastic. The control action is realized within a longer time frame (i.e., 1 minute or 10 minutes instead of 1 second). As before, the desired power at the PCC is known, but it is not used in the control loop; it is used to compute the correspondent energy amount in the control window considered instead. This value is then equally divided in the time frame; it means that, for instance, at half of the period the farm is expected to have produced half the energy expected to be produced in the whole control period.

Thus, the control loop uses the measure of the cumulated energy produced by the turbine each second and compares it with the target energy. If the produced energy is the same (or it is inside a certain band, e.g., $\pm 10 \%$ ) no charge/discharge actions are performed, otherwise the more the distance from the objective value, the deeper the charge/discharge is required. The energy reference value is the energy that the turbine is expected to produce every time frame. This value is then used to create the control energy function (i.e., the blue curve depicted in Figure 3).
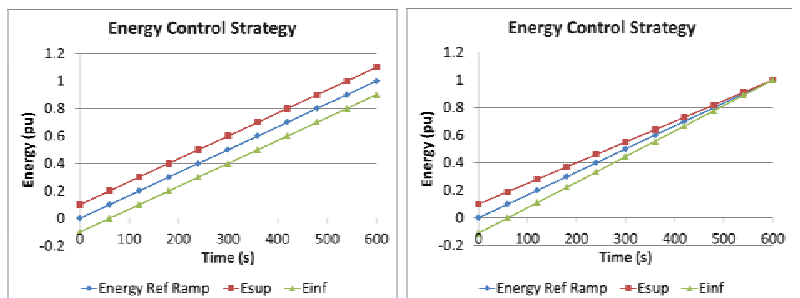

Figure 3. Energy control strategies (parallel on the left, convergent on the right).

The two curves, the red and the green one, form the control band and with this shape (i.e., parallel curves, left picture) there is no warranty that at the end of the period (i.e., at the $600^{\text {th }}$ second) the energy produced will be equal to the reference value. This is due to the fact that this kind of control is a discrete-proportional type, thus a control action is taken if an error is generated but when the control variable is within the band (i.e., the control band) no corrective measurements are taken. If an integral action is intended to be realized the two curves can be designed to be convergent at the end of the control period (right picture of Figure 3). Because of the slower nature of this control the battery reference power output has a ramp limiter of $1 \mathrm{~kW} / \mathrm{s}$.

\section{POWER CONTROL STRATEGY TESTING}

\section{Testing with 8 seconds communication delay}

The first experiment set-up highlighted an important issue related to the communication delay between the PCC measurement and the acquisition of this value in the SCADA. Figure 4 reports in the first diagram the wind turbine production along with the compensation of the battery system. The PCC desired and the real output are reported in the second diagram.

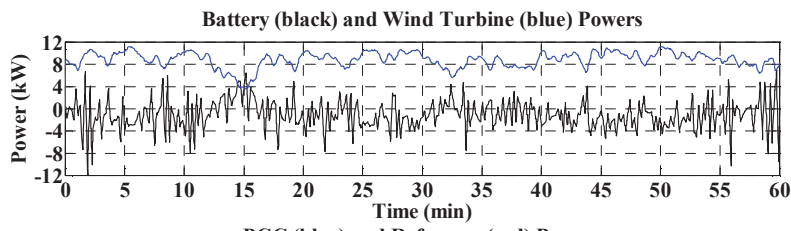
PCC (blue) and Reference (red) Powers

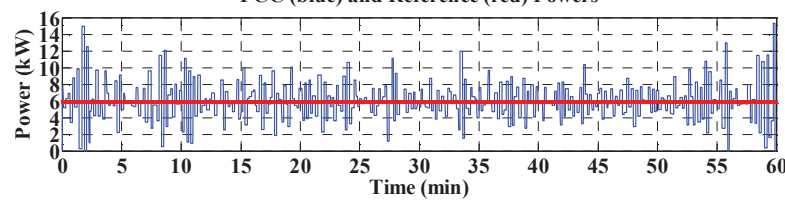

Figure 4. Battery, wind turbine and PCC powers. 
Unfortunately the controlling action is not completely successful (the PCC power is very far from being smoothed) because of the delay that destabilizes the controller. Figure 5 reports the relative frequency on the PCC power profile, it can be seen that the mean value is exactly $6 \mathrm{~kW}$, though the standard deviation is quite high: $2.43 \mathrm{~kW}$ or $0.40 \mathrm{pu}$ if divided by the mean value $(6 \mathrm{~kW})$.

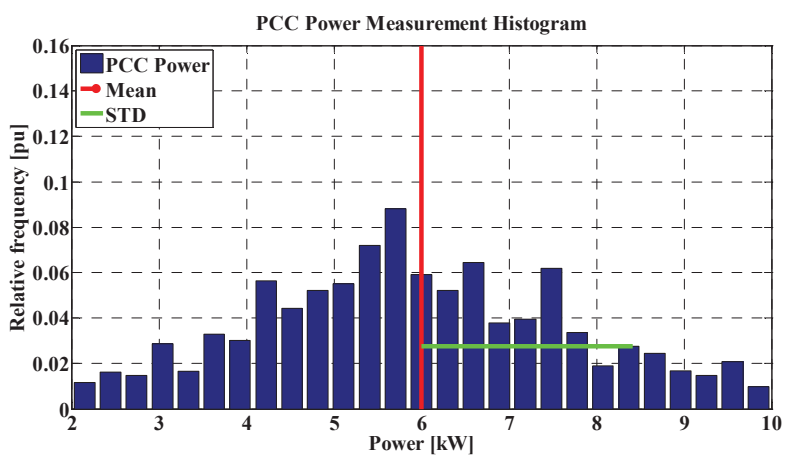

Figure 5. PCC power measurement histogram.

\section{Testing with 1 second communication delay}

In order to reduce the communication time delay, some architectural simplifications in the SCADA system have been performed by disconnecting unused measurement devices. This tuning allowed the system to be much faster, bringing down the delay to 1 second. New measurement campaign has been carried out; in this case, due to lighter wind conditions, the reference value was set to $5 \mathrm{~kW}$ instead of $6 \mathrm{~kW}$. Figure 6 reports the battery and the wind production; the PCC power profile can be appreciated in the second diagram. By the comparison of the histogram of Figure 7 with the previous one, it can be seen how the reduction in the communication time delay granted better performances. The variability of the values around the mean has significantly dropped, as it is highlighted also by the value of the standard deviation, which in this case is equal to $1.05 \mathrm{~kW}$ or $0.21 \mathrm{pu}$ if divided by the mean value $(5 \mathrm{~kW})$.
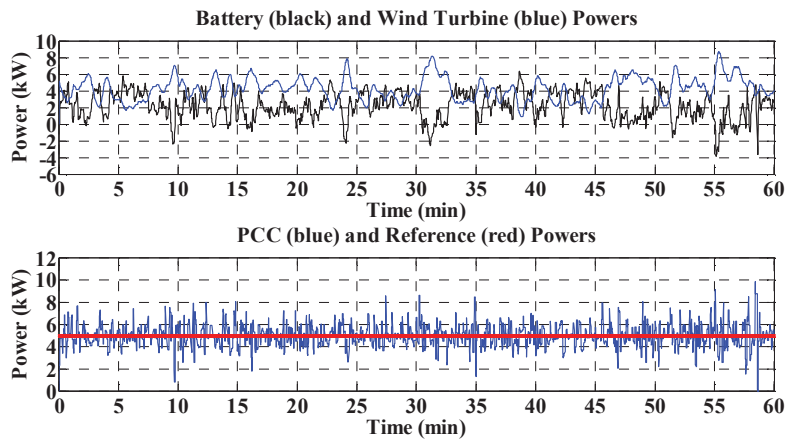

Figure 6. Battery, wind turbine and PCC powers.

Despite of the communication issues, it has also to be remarked the fact that the smoothing action was performed on a single turbine output and that the wind harvested is rather turbulent due to the low mast height.

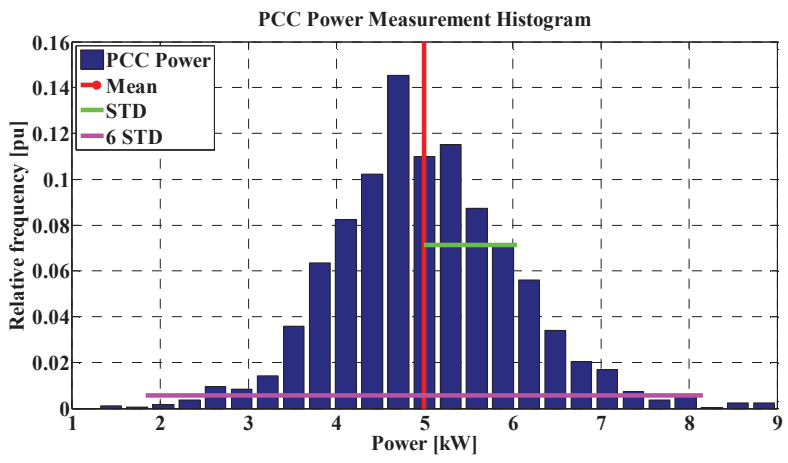

Figure 7. PCC power measurement histogram.

\section{ENERGY CONTROL STRATEGY TESTING}

\section{Testing with 60 seconds time frame}

In this paragraph the results regarding the energy control strategies with a timeframe of 60 seconds are reported. In Figure 8 the actual wind turbine production is shown.

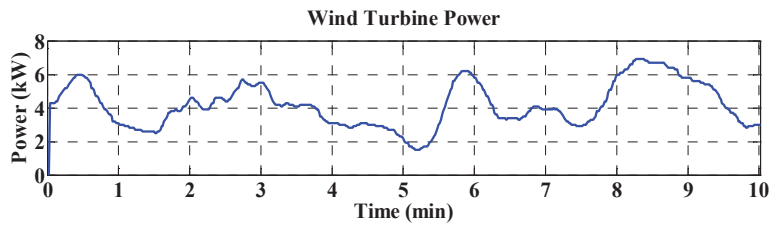

Figure 8. Wind turbine production.

Figure 9 shows the ten minutes length experimental results. At the end of each control window (i.e., 1 minute) the system (battery plus turbine) is asked to produce alternatively $10 / 60 \mathrm{kWh}$ or $5 / 60 \mathrm{kWh}$. The second plot highlights that the errors between the desired energy and the cumulated one at the end of each control frame are well above the $1 \%$ threshold. The reason for that can be searched in the relatively shortness of the control window.

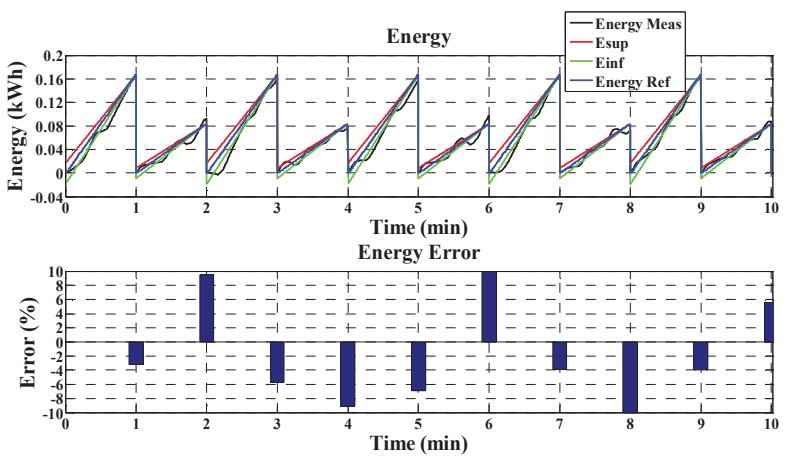

Figure 9. Energy profiles and energy errors.

Figure 10 reports a detailed view of the first control period in order to better appreciate the operation of the control 
strategy. For example, at the $10^{\text {th }}$ second of the experiment, the cumulated energy (black line of the first diagram) goes below the control band (the green one in this case) and that triggers the action of the controller that sets a reference power (red line of the second diagram). The battery output follows with two seconds of delay due to communications and battery system (converter and electrochemistry) dynamics.
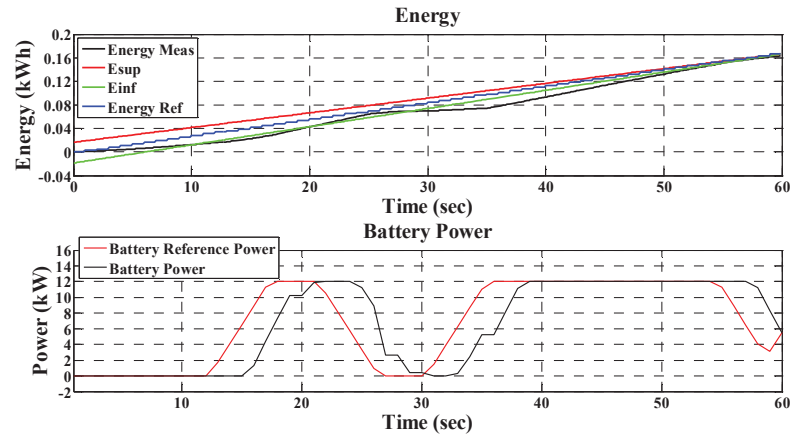

Figure 10. Energy profiles and battery power details.

\section{Testing with 600 seconds time frame}

The last paragraph is devoted to report the results of the energy control experiment with a 600 seconds control window. The amount of energy, shown also in the Figure 11 , is equal to $10 / 6 \mathrm{kWh}$ or $5 / 6 \mathrm{kWh}$.
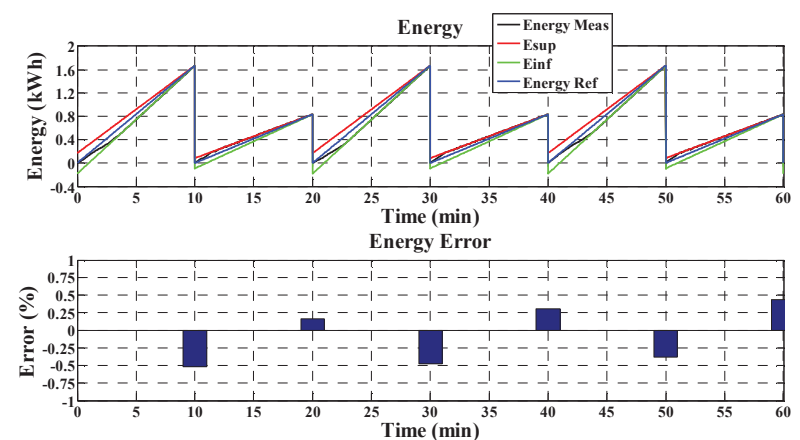

Figure 11. Energy profiles and energy errors.

A one period detail is shown in Figure 12.
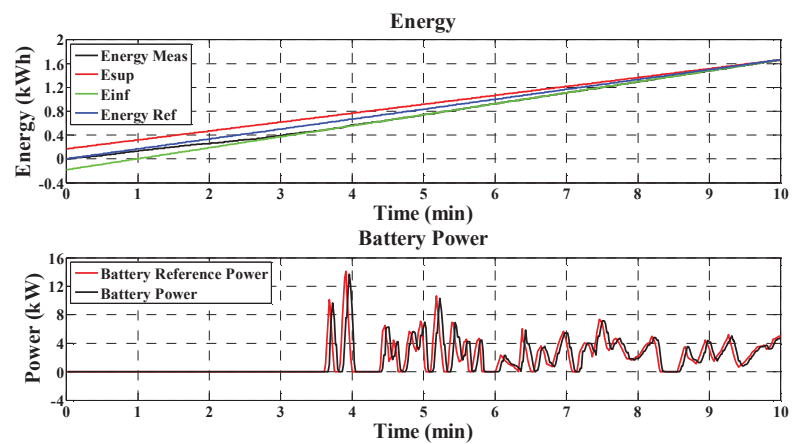

Figure 12. Energy profiles and battery power details.
This time the error is below the $1 \%$ desired threshold, the unavoidable errors at the end of the control period have a lower weight on the energy profile if compared to the previous case.

\section{CONCLUSIONS}

The controller testing has been successful for what concerns the dynamic response of the battery. The battery has proved to be able to pass from full charge to full discharge mode within 2 seconds, being thus able to follow the fast wind turbine output variations during the power control testing. The main challenges were related to the communication time lag and to the wind fast variation. The impact of the communication delay compared to the power dynamic of the wind turbine has been analyzed. The power generation from a single small wind turbine has a significant dynamic in the second scale and the delay in a closed control loop should not exceed $1 \mathrm{sec}$ to perform well. The energy control proved to work well if the control time frame is between 1 minute and 10 minutes. In this case however the PCC power output smoothness cannot be pursued.

Further tests are intended to study control strategies capable to cope with communication delays.

\section{ACKNOWLEDGEMENTS}

Part of this work was supported by EU funding through the DERRI Project under grant ID 20110531-02 (Wind power and Storage modeling and Integrated Control in electric distribution systems) and ID 20110531-04 (Renewable Energy Sources and Storage for Integrated Control in electric distribution system).

\section{REFERENCES}

[1] R. J. Thomas, "Putting an action plan in place," IEEE Power Energy Mag., vol. 7, no. 4, pp. 26-31, Jul./Aug. 2009.

[2] D. Di Rosa, I. Fastelli, G. Gigliucci, S. Grillo, M. Marinelli, S. Massucco, F. Silvestro, "Generation and battery modelling and integrated control strategies for a better acceptance of intermittent renewable energy sources in the electric distribution system", CIRED Workshop, pp. 1-4, Lyon, 7-8 Jun. 2010.

[3] T. Funabashi, Y. Kikunaga, A. Y. Saber, H. Sekine, T. Senjyu and A. Yona, "Coordinate Control of Wind Turbine and Battery in Wind Power Generation System", IEEE Power and Energy Society General Meeting, pp. 1-7, Pittsburgh, 20-24 Jul. 2008.

[4] F. Baccino, S. Grillo, M. Marinelli, S. Massucco, F. Silvestro, "Power and Energy Control Strategies for a Vanadium Redox Flow Battery and Wind Farm Combined System", IEEE ISGT 2011, pp. 1-8, Manchester, 5-7 Dec. 2011.

[5] IEEE Standard, "IEEE Recommended Practice for Energy Management in Industrial and Commercial Facilities", IEEE Std 739-1995, pp. 1-297, 1996. 